\title{
Efeito do estresse hídrico e térmico na germinação e no vigor de sementes de cenoura
}

\author{
Effect of heat and water stress on germination and vigour of carrot seeds \\ Marcelo C. de C. Silva ${ }^{1 *}$, André F. A. Medeiros ${ }^{2}$, Denise C. F. dos S. Dias ${ }^{3}$, \\ Eveline M. Alvarenga, Fabrício S. Coelho ${ }^{2}$, Heder Braun ${ }^{2}$
}

\begin{abstract}
RESUMO
O objetivo deste trabalho foi avaliar o efeito do estresse hídrico e térmico na germinação e no vigor de sementes de cenoura. Foram conduzidos dois experimentos na Universidade Federal de Viçosa, utilizando-se três lotes de sementes de cenoura, sendo o lote 1 do cv. "Carandaî", os lotes 2 e 3 do cv. "Brasília". No experimento 1 - Estresse hídrico - Quatro potenciais osmótico, 0,0; -0,3; -0,6 e -0,9 MPa foram utilizados para o umedecimento do papel substrato, com uma solução de PEG 6000 nas concentrações de $0 ; 17,16$; 25,68 e $32,16 \mathrm{~g} \mathrm{~L}^{-1}$. As sementes foram, então, avaliadas quanto à germinação e ao vigor . Para o experimento 2 - Estresse térmico - Três temperaturas, 15,20 e $35^{\circ} \mathrm{C}$, foram utilizadas na condução dos testes para avaliação da qualidade das sementes. Utilizou-se como substrato para as sementes o papel toalha umedecido com água, na proporção de 2,5 vezes o peso do papel. Conclui-se que a germinação das sementes de cenoura não foi afetada até potenciais de $-0,3 \mathrm{MPa}$. O comprimento da radícula e a primeira contagem de germinação foram eficientes para avaliar o vigor das sementes de cenoura, sob estresse hídrico e térmico, permitindo a classificação dos lotes testados. Temperaturas de 15 e $35^{\circ} \mathrm{C}$ influenciaram negativamente a germinação e o vigor das sementes de cenoura.

Palavras chave: Daucus Carota L.; sementes; potencial osmótico; temperatura.
\end{abstract}

\section{ABSTRACT}

The objective of this study was to evaluate the effect of water and thermal stress on the germination and vigor of carrot seeds. Two experiments were performed in the Universidade Federal de Viçosa; three lots of carrot seeds were used, lot 1 of cv. "Carandai " and the lots 2 and 3 of cv. "Brasília ". In experiment 1 - Water stress - Four osmotic potentials, 0.0; -0.3; -0.6 and -0.9 MPa were used to humidify the paper substratum, with a solution of PEG 6000 in concentrations of $0 ; 17.16 ; 25.68$ and $32.16 \mathrm{~g} \mathrm{~L}^{-1}$. Germination and vigor were estimated. For experiment 2 - Thermal stress - Three temperatures were used, $15^{\circ}, 20^{\circ}$ and $35^{\circ} \mathrm{C}$, to evaluate the quality of the seeds. It A paper towel humidified with water was used as substratum, in the proportion of 2.5 times the weight of the paper. It is concluded that the germination of the carrot seeds was not affected by potentials of-0.3 MPa. The length of the roots and the first germination count were efficient to evaluate the vigor of the carrot seeds, under water and thermal stress, allowing the classification of the tested lots. Temperatures of $15^{\circ}$ and $35^{\circ} \mathrm{C}$ influenced the germination and the vigor of the carrot seeds negatively.

Key words: Daucus Carota L.; seeds; osmotic potential; temperature.

\section{Introdução}

As sementes, por ocasião do plantio, estão sujeitas a diversos fatores ambientais como déficit hídrico, oscilações na temperatura, competição com plantas daninhas, ataque de pragas e doenças, entre outros, que pode acarretar redução na percentagem e velocidade de emergência das plântulas, ocasionando um estande desuniforme, e conseqüentemente, diminuição na produção.
A água é um dos fatores primordiais para a semente aumentar a sua atividade metabólica, iniciando a absorção (fase I) nas primeiras seis horas segundo McDonald et al. (1994), o que acarreta um suprimento de energia e nutrientes para reativar o metabolismo e promover a protrusão da radícula (Bewley \& Black, 1994). A absorção de água, entretanto é influenciada pela textura do solo, potencial matricial e temperatura (Carvalho \& Nakagawa, 2000).

1 Pós-Doutor em Fitotecnia UFV, Rua: Prudente de Morais 1143, Bairro: Santo Antônio, CEP: 59611-100 Mossoró-RN.

2 Universidade Federal de Viçosa/UFV, Departamento de Fitotecnia, Av. PH Rolfs, s/n. Campus Universitário. CEP: 36570-000, Viçosa-MG, Brasil.

2 Professora Departamento de Fitotecnia/UFV, Av. PH Rolfs, s/n. Campus Universitário. CEP: 36570-000, Viçosa-MG, Brasil. * e-mail corresponding author: mdecastro70@yahoo.com.br

Fecha de Recepción: 19 Abril, 2010.

Fecha de Aceptación: 24 Enero, 2011. 
Para cada espécie há um potencial hídrico no solo, abaixo do qual as sementes não germinam. Especialmente no início da embebição, potenciais hídricos muito baixos influenciam a absorção de água, inviabilizando diversos processos fisiológicos. A embebição prolongada, sob baixos potenciais hídricos, por sua vez, é extremamente prejudicial à germinação das sementes, podendo ocorrer a morte do embrião (Hobbs \& Obendorf, 1972).

Condições de déficit hídrico geralmente são simuladas pelo uso dos agentes osmóticos como manitol e polietileno glicol, que são produtos atóxicos e inertes (Villela et al., 1991). Como tais substâncias são pouco absorvidas pelas sementes durante o processo de germinação destas substâncias é similar ao exercido pelas partículas coloidais do solo (Parmer \& Moore, 1968).

El-Sharkawi \& Springuel (1977) ao simularem o efeito da redução do potencial matricial na germinação do trigo, cevada e sorgo, utilizando polietileno glicol, observaram que as sementes respondiam diferentemente à redução do potencial mátrico. A emergência da plúmula foi mais sensível à redução do potencial hídrico do que a emergência da radícula. $\mathrm{O}$ início da germinação ocorreu a um potencial de $-0,17 ;-0,10$ e $-0,7 \mathrm{MPa}$ em trigo, cevada e sorgo, respectivamente.

Pesquisando a influência do estresse hídrico e térmico no desempenho germinativo de sementes de cenoura, Carneiro et al., 1999 observaram que quando as sementes foram submetidas ao estresse hídrico (PEG -0,05; -0,15 e -0,25 MPa) houve redução do percentual máximo de germinação. $O$ desempenho das sementes também foi prejudicado pelo estresse térmico quando estas foram expostas a temperatura de $40{ }^{\circ} \mathrm{C}$ a partir de 12 horas.

É importante salientar que a temperatura de germinação das sementes é outro fator importante para a eficiência do processo, pois ela afeta a velocidade de embebição da semente. A temperatura utilizada para germinação de sementes de hortaliças varia, de uma maneira geral, de 15 a $25^{\circ} \mathrm{C}$. Para sementes de cenoura o melhor desempenho foi obtido com a temperatura de $25{ }^{\circ} \mathrm{C}$ em trabalho de Carneiro \& Guedes (1992), embora as Regras para Análise de sementes (BRASIL, 1992) recomendem $20^{\circ} \mathrm{C}$ constante ou $20-30{ }^{\circ} \mathrm{C}$ alternadas.

O presente trabalho teve por objetivo avaliar o efeito do estresse hídrico e térmico na germinação e no vigor de sementes de cenoura.

\section{Material e Métodos}

Foram conduzidos dois experimentos no Laboratório de Pesquisa de Sementes do Departamento de Fitotecnia da Universidade Federal de Viçosa (UFV), utilizando-se três lotes de sementes de cenoura, sendo o lote 1 do cv. "Carandaî", os lotes 2 e 3 do cv. "Brasília", com germinação inicial de 72,89 e $77 \%$, respectivamente.

No experimento onde avaliou o efeito do estresse hídrico foram utilizados quatro potenciais osmóticos $(0,0 ;-0,3 ;-0,6 \mathrm{e}-0,9 \mathrm{MPa})$ para o umedecimento do papel substrato, com uma solução de Polyethylene Glycol (PEG 6000) nas concentrações de 0; 17,16; 25,68 e 32,16 $\mathrm{g} \mathrm{L}^{-1}$ a fim de simular um déficit hídrico. Para avaliar o efeito do estresse térmico três temperaturas $\left(15,20\right.$ e $\left.35^{\circ} \mathrm{C}\right)$ foram utilizadas na condução dos testes para avaliação da qualidade das sementes.

As sementes foram, então, avaliadas quanto à germinação e vigor, empregando-se os seguintes testes e determinações:

Germinação - realizado com quatro repetições de 50 sementes de cada lote, distribuídas sobre 3 folhas de papel toalha umedecido com soluções de PEG 6000 nas concentrações de 0; 17,16; 25,68 e $32,16 \mathrm{~g} \mathrm{~L}^{-1}$ em quantidade equivalente a 2,5 vezes o peso, em caixas plásticas transparentes (gerbox). Posteriormente, estas foram colocadas em germinador regulado para manter a temperatura constante de $20^{\circ} \mathrm{C}$. Para avaliar o efeito do estresse térmico utilizou-se como substrato para as sementes o papel toalha umedecido com água na proporção de 2,5 vezes o peso do papel sendo, posteriormente, os gerbox mantidos nas temperaturas de 15,20 e 35 ${ }^{\circ} \mathrm{C}$. As contagens foram efetuadas aos 9 dias após a semeadura para o estresse térmico e aos 9 e 14 dias para o estresse hídrico.

Primeira contagem - realizada conjuntamente com o teste de germinação, consistiu do registro das porcentagens de plântulas normais verificadas na primeira contagem do teste de germinação, feita no nono dia após a semeadura, seguindo as prescrições das Regras para Análise de Sementes (BRASIL, 1992)

Comprimento da radícula $(\mathbf{C R})$ - foram utilizadas quatro subamostras de dez sementes distribuídas em uma linha sobre duas folhas de papel toalha umedecidas e levadas para germinar a temperatura $20^{\circ} \mathrm{C}$. Para o estresse térmico, utilizaram-se quatro subamostras de dez sementes 
distribuídas em linha sobre duas folhas de papel toalha e levadas para germinar nas temperaturas de 15,20 e $35^{\circ} \mathrm{C}$. O tempo de permanência das sementes nas soluções e temperaturas foi de 7 e 14 dias após a semeadura, época em que foram feitas avaliações do comprimento da radícula $(\mathrm{cm})$, obtendo-se um valor representado pela divisão do somatório dos comprimentos verificados, independentemente da classificação da normalidade das plântulas, pelo número total de indivíduos da população.

Índice de velocidade de germinação (IVG) e velocidade de germinação (VG) - foram conduzidos anotando-se, no teste de germinação, de 24 em 24 horas, do sétimo ao décimo quarto dia após a semeadura, o número de plântulas que germinaram, ou seja, as que apresentavam radícula maior ou igual a $4 \mathrm{~cm}$ de comprimento. O IVG foi calculado empregando-se a fórmula proposta por Maguire (1962). A VG foi obtida através da média aritmética dos valores do teste de germinação, segundo Edmond \& Drapala (1958).

Para a análise de variância, apenas os dados obtidos em porcentagem, foram previamente transformados em arco-seno $\sqrt{X / 100}$ para os dados quantitativos foram realizado análise de regressão e as comparações entre as médias foi realizada através do teste de Tukey, ao nível de 5\% de probabilidade.

\section{Resultados e Discussão}

As sementes de cenoura dos diferentes lotes apresentaram redução na germinação sob baixos potenciais osmóticos. No lote 2 as sementes mantiveram alta germinação até o potencial $-0,3 \mathrm{MPa}$, a partir daí as reduções na germinação foram semelhante aquelas ocorridas nas sementes dos lotes 1 e 3. Os valores de germinação dos três lotes nos potenciais osmóticos de $-0,6 \mathrm{e}-0,9 \mathrm{MPa}$ foram muito baixos (Figura 1), concordando com Adegbuyi et al. (1981) que relata uma redução na germinação quando as sementes de soja são submetidas a baixos potenciais hídricos.

A avaliação do vigor dos lotes de sementes de cenoura, submetidas a diferentes estresses hídricos, mostrou que no lote 2 houve maior comprimento de radícula das plântulas em relação àquelas dos lotes 1 e 3. Uma situação de déficit hídrico no ambiente de semeadura reflete numa menor embebição das sementes. Sementes mais vigorosas são menos afetadas que as demais (Tabela 1).

Embora pelos resultados do índice de velocidade de germinação (IVG) e da velocidade de germinação em dias (VG), não tenham sido evidenciadas diferenças significativas entre os lotes de sementes de cenoura, a primeira contagem do teste

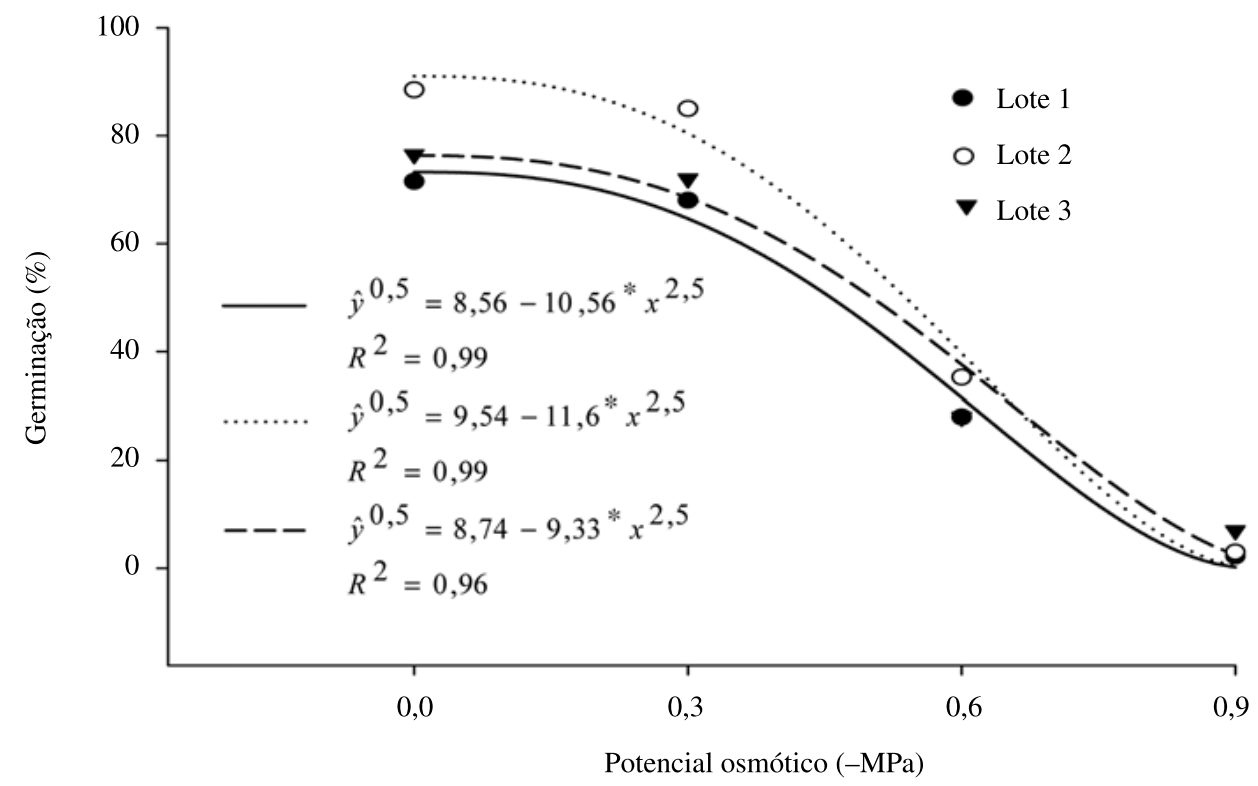

Figura 1. Efeito do potencial osmótico na germinação de sementes de cenoura. Viçosa, UFV, 2004. 
Tabela 1. Efeito do estresse hídrico no vigor de lotes de sementes de cenoura. Viçosa, MG, 2004.

\begin{tabular}{lcccc}
\hline Lote & CR $(\mathrm{cm})$ & IVG & VG (dias) & $1{ }^{\mathrm{a}}$ Contagem da Germinação (\%) \\
\hline 1 & $3,73 \mathrm{~b}$ & $0,62 * \mathrm{a}$ & $8,73 \mathrm{a}$ & $36,00 \mathrm{~b}$ \\
2 & $4,48 \mathrm{a}$ & $0,83 \mathrm{a}$ & $8,14 \mathrm{a}$ & $66,50 \mathrm{a}$ \\
3 & $3,25 \mathrm{~b}$ & $0,71 \mathrm{a}$ & $8,57 \mathrm{a}$ & $22,57 \mathrm{c}$ \\
$\mathrm{CV}(\%)$ & 13,60 & 26,03 & 9,00 & 13,89 \\
\hline
\end{tabular}

* Médias seguidas pela mesma letra na coluna, não diferem entre si através do teste de Tukey ao nível de 5\% de probabilidade.

Tabela 2. Efeito do estresse hídrico no vigor de lotes de sementes de cenoura. Viçosa, MG, 2004.

\begin{tabular}{lccc}
\hline Potencial osmótico $(\mathrm{MPa})$ & $\mathrm{CR}(\mathrm{cm})$ & IVG & VG (dias) \\
\hline 0 & $4,44^{*} \mathrm{a}$ & $0,96 \mathrm{a}$ & $8,27 \mathrm{a}$ \\
$-0,3$ & $3,20 \mathrm{~b}$ & $0,48 \mathrm{~b}$ & $8,69 \mathrm{a}$ \\
$\mathrm{CV}(\%)$ & 13,60 & 26,03 & 9,00 \\
\hline
\end{tabular}

* Médias seguidas pela mesma letra na coluna, não diferem entre através do teste de Tukey ao nível de 5\% de probabilidade.

Tabela 3. Efeito da interação entre o potencial osmótico e lotes de sementes de cenoura, na primeira contagem do teste de germinação. Viçosa, MG, 2004.

\begin{tabular}{lcc}
\hline \multirow{2}{*}{ Lote } & \multicolumn{2}{c}{ Potencial osmótico (MPa) } \\
\cline { 2 - 3 } & \multicolumn{1}{c}{$1^{\mathrm{a}}$ Contagem da Germinação (\%) } \\
\cline { 2 - 3 } & 0,0 & $-0,3$ \\
\hline 1 & $34,00 * \mathrm{Ab}$ & $38,00 \mathrm{Ab}$ \\
2 & $68,50 \mathrm{Aa}$ & $64,50 \mathrm{Aa}$ \\
3 & $30,50 \mathrm{Ab}$ & $14,65 \mathrm{Bc}$ \\
$\mathrm{CV}(\%)$ & & 13,89 \\
\hline
\end{tabular}

* Médias seguidas da mesma letra maiúscula nas linhas e minúsculas nas colunas não diferem entre si através do teste de Tukey ao nível de 5\% de probabilidade.

de germinação mostrou que, realmente, o lote 2 teve um maior vigor em condição de estresse hídrico, do que os lotes 1 e 3 .

$\mathrm{O}$ vigor das sementes, avaliado pelo crescimento radicular (CR) das plântulas de cenoura, foi afetado pelo potencial osmótico de $-0,3 \mathrm{MPa}$ conforme resultados apresentados na Tabela 02 . Torres (1996) estudando a eficiência da utilização do estresse hídrico na avaliação da qualidade fisiológica de sementes de pimentão, utilizando PEG 6000 , também constatou redução progressiva do crescimento das plântulas com o decréscimo do potencial de 0,0 para $-0,3 \mathrm{MPa},-0,6 \mathrm{MPa}$ e $-0,9$ $\mathrm{MPa}$, concluindo que o comprimento das plântulas a um potencial de $-0,3 \mathrm{MPa}$, pode ser utilizado para estimar o desempenho destas sementes. Em sementes de soja, Rosseto et al. (1997) observaram decréscimo acentuado na percentagem de emissão da raiz primária das sementes quando o potencial hídrico passou de -0,2 para-0,40 MPa. Além do estresse hídrico afetar a embebição, a velocidade e a percentagem de germinação, Kramer (1974) relata que o primeiro efeito mensurável do estresse hídrico é uma diminuição do crescimento, causada pela diminuição da expansão celular. $\mathrm{O}$ processo de alongamento celular e a síntese de parede são altamente sensíveis ao déficit hídrico (Wenkert et al., 1978), o que levaria a redução do crescimento causada por um decréscimo na turgescência celular.

A velocidade de germinação das sementes também foi afetada pelo baixo potencial osmótico $(-0,3 \mathrm{MPa})$ a que foram submetidas, sendo que o IVG foi mais sensível que o $\mathrm{VG}$ para detectar diferenças entre os dois potenciais testados, confirmando que $\mathrm{o}$ vigor das sementes foi realmente afetado quando germinadas a $-0,3 \mathrm{MPa}$ (Tabela 2).

Analisando a interação entre o potencial osmótico e os lotes de sementes de cenoura em relação à primeira contagem do teste de germinação foi possível classificar, com uma maior precisão, o vigor dos três lotes de sementes de cenoura: 2 (alto vigor), 1 (baixo vigor) e 3 (muito baixo vigor), no potencial -0,3 MPa (Tabela 3).

A avaliação do vigor das sementes nas diferentes temperaturas (estresse térmico) permitiu comprovar a superioridade do lote 2 em relação aos demais. $\mathrm{O}$ menor crescimento radicular observado nas sementes do lote 3 indica que este lote apresenta uma maior sensibilidade à temperaturas baixas e acima daquela considerada ótima, ou seja, em condições de estresse térmico (Tabela 4). A velocidade de germinação das sementes, avaliado pelas variáveis IVG e VG, apenas permitiram destacar o lote 2, enquanto a primeira contagem do teste de germinação, permitiu classificar os três lotes, sendo desta forma mais indicado para avaliar a qualidade das 
Tabela 4. Efeito do estresse térmico no vigor e na germinação de lotes de sementes de cenoura. Viçosa, MG, 2004.

\begin{tabular}{lcccc}
\hline Lote & CR $(\mathrm{cm})$ & IVG & VG (dias) & $1^{\text {a }}$ Contagem da Germinação $(\%)$ \\
\hline 1 & $2,72 * a$ & $0,75 \mathrm{~b}$ & $8,92 \mathrm{a}$ & $56,83 \mathrm{c}$ \\
2 & $2,97 \mathrm{a}$ & $1,02 \mathrm{a}$ & $7,97 \mathrm{~b}$ & $79,83 \mathrm{a}$ \\
3 & $2,02 \mathrm{~b}$ & $0,75 \mathrm{~b}$ & $8.86 \mathrm{a}$ & $66,08 \mathrm{~b}$ \\
$\mathrm{CV}(\%)$ & 14,29 & 22,37 & 6,99 & 8,85 \\
\hline
\end{tabular}

* Médias seguidas pela mesma letra na coluna, não diferem entre si através do teste de Tukey ao nível de 5\% de probabilidade.

sementes de cenoura, quando submetidas a estresse térmico (Tabela 4).

A temperatura de $20^{\circ} \mathrm{C}$, como era de se esperar já que é recomendada para cenoura (BRASIL, 1992), proporcionou um maior crescimento radicular, ou seja, proporcionou um maior desenvolvimento das plântulas do que a 35 e $15^{\circ} \mathrm{C}$. Foi possível identificar diferenças significativas no desenvolvimento das plântulas nas três temperaturas, indicando que, como falado anteriormente para a primeira contagem, também o comprimento de radícula (CR) é um bom parâmetro para avaliar o vigor de sementes de cenoura em condições de estresse térmico (Tabela 5).

Quando colocadas para germinar a 20 e a 35 ${ }^{\circ} \mathrm{C}$, as sementes dos três lotes estudados não apresentaram diferenças entre si quanto à velocidade de emergência, mas sob $15^{\circ} \mathrm{C}$ o lote 2 germinou mais rápido que os lotes 1 e 3 (Tabela 6 ). O desempenho de cada lote, submetido a diferentes temperaturas, deixou claro que o lote 2 não foi influenciado quando exposto a diferentes temperaturas, mostrando um maior vigor perante as condições de estresse térmico (Tabela 6).

\section{Conclusões}

A germinação das sementes de cenoura não foi afetada até potenciais de $-0,3 \mathrm{MPa}$.

O comprimento da radícula e a primeira contagem de germinação foram eficientes para avaliar o vigor das sementes de cenoura, sob estresse hídrico e térmico, permitindo a classificação dos lotes testados.

Temperaturas de 15 e $35^{\circ} \mathrm{C}$ influenciaram negativamente a germinação e o vigor das sementes de cenoura.

Tabela 5. Efeito do estresse térmico no vigor e na germinação de lotes de sementes de cenoura. Viçosa, MG, 2004.

\begin{tabular}{lcccc}
\hline Temperatura $\left({ }^{\circ} \mathrm{C}\right)$ & $\mathrm{CR}(\mathrm{cm})$ & IVG & VG (dias) & $1^{\text {a }}$ Contagem da Germinação $(\%)$ \\
\hline 15 & $2,28 * \mathrm{~b}$ & $0,79 \mathrm{ab}$ & $9,57 \mathrm{a}$ & $59,08 \mathrm{~b}$ \\
20 & $4,44 \mathrm{a}$ & $0,96 \mathrm{a}$ & $8,27 \mathrm{~b}$ & $78,83 \mathrm{a}$ \\
35 & $0,98 \mathrm{c}$ & $0,77 \mathrm{~b}$ & $7,90 \mathrm{~b}$ & $64,83 \mathrm{~b}$ \\
$\mathrm{CV}(\%)$ & 14,29 & 22,37 & 6,99 & 8,85 \\
\hline
\end{tabular}

* Médias seguidas pela mesma letra na coluna, não diferem entre si através do teste de Tukey ao nível de 5\% de probabilidade.

Tabela 6. Efeito da interação entre temperatura e lote de sementes, na velocidade de germinação de sementes de cenoura. Viçosa, MG, 2004.

\begin{tabular}{lccc}
\hline & \multicolumn{3}{c}{ Temperatura $\left({ }^{\circ} \mathrm{C}\right)$} \\
\cline { 2 - 4 } Lote & 15 & 20 & 35 \\
\cline { 2 - 4 } & & Velocidade de germinação (dias) & $8,48 \mathrm{Ba}$ \\
1 & $9,84 * \mathrm{Aa}$ & $8,44 \mathrm{Ba}$ & $7,62 \mathrm{Aa}$ \\
2 & $8,49 \mathrm{Ab}$ & $7,80 \mathrm{Aa}$ & $7,60 \mathrm{Ba}$ \\
3 & $10,40 \mathrm{Aa}$ & $8,57 \mathrm{Ba}$ & \\
$\mathrm{CV}(\%)$ & & 6,99 & \\
\hline
\end{tabular}

* Médias seguidas da mesma letra maiúscula nas linhas e minúsculas nas colunas não diferem através do teste de Tukey ao nível de $5 \%$ de probabilidade. 


\section{Referências Citadas}

Adegbuyi, E.; Cooper, S.R.; Don, R.

1981 Osmotic priming of some herbage grass seed using polyethylene glycol (PEG). Seed Science and Technology, v. 9 , n. 3, p. 867-878.

Bewley, J.D.; Black, M.

1994 Seeds: physiology of development and germination. 2 ed. New York: Plenum Press, 445 p.

Brasil

1992 Ministério da Agricultura e da Reforma Agrária. Regras para análise de sementes. Brasília, SNDA/DNDV/CLAV. $365 \mathrm{p}$.

Carneiro, J.W.P.; Guedes, T.A.

1992 Influência da temperatura no desempenho germinativo de sementes de cenoura (Daucus carota L.) avaliada pela função de distribuição de Weibull. Revista Brasileira de Sementes, v. 14, n. 2, p. 207-213.

Carneiro, J.W.P.; Braccini, A.L.; Guedes, T.A.; Amaral, D. 1999 Influência do estresse hídrico, térmico e do condicionamento osmótico no desempenho germinativo de sementes de cenoura (Daucus carota L.). Revista Brasileira de Sementes, v. 21, n. 2 , p. $208-216$.

Carvalho, N.M.; Nakagawa, J.

2000 Sementes: ciência, tecnologia e produção. 4ed. Jaboticabal: FUNEP. 588 p.

Edmond, J.B.; Drapala, W.J.

1958 The effects of temperature, sand and soil, and acetone on germination of okra seeds. Proceeding American Society Horticultural Science, v. 71, p. 428-34.

El-Sharkawi, H.M.; Springuel, I.

1977 Germination of some crop plant seeds under reduced water potential. Seed Science and Technology, v. 5, p. 677-688.

Hobbs, P.R.; Obendorf, R.L.

1972 Interaction of initial seed moisture and imbibitional temperature on germination and productivity of soybean. Crop Science, v. 13, p. 664-667.
Kramer, P.J.

1974 Fifty years of progress in water relations research. Plant Physiology, v. 54, p. 463-471.

Maguire, J.D.

1962 Speed of germination-aid in selection and evaluation for seedling emergence and vigor. Crop Science, v. 2, n. 1, p. 176-177.

Mcdonald, M.B.; Sulivan, J.; Lauer, M.J.

1994 The pathway of water uptake in maize seeds. Seed Science and Technology, v. 22, n. 1, p. 79-90.

Parmer, M.Y.; Moore, R.P.

1968 Carbowax 6000, manitol and sodium chloride for simulating drought (Zea mays L.) of strong and weak vigour. Agronomy Journal, v. 60, n. 2, p. 92-195.

Rosseto, C.A.V.; Novembre, A.D.L.C.; Marcos Filho, J.; Silva, W.R.; Nakagawa, J.

1997 Efeito da disponibilidade hídrica no substrato, da qualidade fisiológica e do teor de água inicial das sementes de soja no processo de germinação. Scientia Agrícola, v. 54, p. 97-105.

Torres, S.B.

1996 Qualidade fisiológica de sementes de pimentão (Capsicum annиum L.) através do teste de estresse hídrico. Revista Brasileira de Sementes, v. 18, n. 2, p. 246-250.

Villela, F.A.; Doni Filho, L.; Siqueira, E.L.

1991 Tabela de potencial osmótico em função da concentração de polietileno glicol 6.000 e da temperatura. Pesquisa Agropecuária Brasileira, v. 26, n. 11/12, p. 1957-1968.

Wenkert, W.; Lemon, E.R.; Sinclair, T.R.

1978 Leaf elongation and turgor pressure in field; grown soybean. Agronomy Journal, v. 70, p. 761-764. 